\title{
An exploratory study of Heads of Departments' responses to student calls for decolonised higher education
}

\section{Callie Grant}

Education Department, Rhodes University

c.grant@ru.ac.za

https://orcid.org/0000-0002-4188-7408

\section{Lynn Quinn}

Centre for Higher Education Research, Teaching and Learning, Rhodes University

1.quinn@ru.ac.za

https://orcid.org/0000-0002-2922-1312

\section{Jo-Anne Vorster}

Centre for Higher Education Research, Teaching and Learning, Rhodes University

j.vorster@ru.ac.za

(Received: 28 April 2018; accepted: 17 August 2018)

\section{Abstract}

Central to the tumultuous student protests of 2015 and 2016 was an urgent call for the decolonisation of South African universities. Existing curricula, including teaching and assessment practices, as well as institutional cultures and structures were challenged. Against this backdrop, in this article we focus on the academic leadership role of Heads of Departments (HoDs) at Rhodes University. In this small-scale project we interrogate how HoDs conceptualised their roles in this uncertain and complex context. From the data analysis a number of tensions emerged in the ways in which they articulated and enacted their roles. The findings indicate that the protests have contributed to the increasing complexity of the role of an HoD. Issues raised during the protests catalysed HoDs at Rhodes University, some for the first time, into considering the implications of the decolonising call from students and into exercising stronger transformative leadership roles.

Keywords: decolonisation, academic leadership, Heads of Department, cultural historical activity theory

\section{Contextual framing}

The impetus for research reported on here was the student protests experienced at many South African universities in 2015 and 2016. Student protests of one kind or another have been a feature of the education landscape since the Soweto Riots in 1976. At the heart of student protests in South Africa have been calls to eradicate the pernicious effects of colonial 
rule and apartheid policies on education. The reasons for these protests are complex and varied. Becker (2017), has argued that a full analysis can be undertaken only once all the economic, political, psychosocial, and historical influences have been analysed. It is not our intention in this article to undertake such an analysis of student protests across the sector. Although student protests have been common at historically black institutions for decades, of interest to us was the response to the protests at historically white institutions (HWIs) such as Rhodes University.

Rhodes was established in 1904, to "bolster the British imperial connection" (Maylam, 2005, p.14) and many still regard it as a colonial institution. Despite the work of individuals and groups who have fought against the effects of colonialism and apartheid at Rhodes for decades, the events of 2015 and 2016 showed that

although Rhodes University prides itself on being a liberal, diverse, universal and accepting space, for many students Rhodes is not. It is rather a home for those who are white and middle class, or those who are prepared to assimilate into whiteness and the middle class. (Alasow, 2015, n.p.)

For Meth (2017), "It is arguable whether there has been any significant opening up of spaces at Rhodes for the flowering of epistemologies, ontologies, theories and questions other than those that have long been hegemonic and that have exercised dominance" (p. 105). Rhodes ranks regularly as the university with the best undergraduate pass rates in the country. However, on closer scrutiny it is clear that pass rates are still skewed along racial lines with proportionately many more black than white students failing and dropping out. The recent protests at Rhodes were fuelled largely by black students calling for the decolonisation of an institution that they experienced as alienating, partly because it is modeled on traditional British universities that valorise Western forms of knowledge and pedagogy. Students critiqued the hidden middle-class values that characterise Rhodes.

Rhodes experienced three sets of student protests, one related to sexual violence, another that focused on the untransformed institutional culture of the institution, and the more widespread ones calling for free higher education. Each of these protests has prompted some academics and academic leaders to think much more critically about the ways in which ideas, beliefs, values, and academic histories influence curricula and pedagogic choices.

In this article we report on the findings of a small slice of the data from a case study in which we probed whether and how the protests conscientised HoDs at Rhodes to think differently about their roles as academic leaders. We argue that at Rhodes, and perhaps at other HWIs, it was as a result of these protests, experienced by some as sudden and unexpected, that many academics and academic leaders began, for the first time, to understand how their taken-forgranted curricula, choices of knowledge, teaching and assessment methods were affecting the majority of black students.

In the first part of the article we provide a brief overview of the causes and implications of the student protests, predominantly at HWIs. Next, we explore the changing roles of HoDs 
brought about by increased pressure as a consequence of the growing demands from within and beyond the universities themselves. We argue that HoDs play a crucial role in how academics engage with one another and with students about the academic projects in their disciplines. Following that we outline the methodology of the study. We conclude with a discussion on what our study uncovered about how HoDs at Rhodes understood their roles and their responses to the students' calls for the decolonisation of Higher Education (HE).

\section{Student protests: 2015 and 2016}

In South Africa, after 1994, there was an awareness of the strong imperative to transform all aspects of the HE sector to eradicate the negative effects of colonialism and apartheid. Although there have been some changes, the sector has remained largely untransformed. In 2009, Saleem Badat, then vice-chancellor of Rhodes, wrote that

the troublesome stasis and continuities in conditions and institutions include: limited access to students from working-class and rural poor social origins, the social composition of academic staff which remains largely white, limited decolonisation, de-racialisation and de-gendering of knowledge production, and institutional cultures dominated by historical tradition. (p. 455)

By early 2015, the bubbling discontent with the status quo among many students erupted in the form of widespread student protests at South African (SA) universities. At HWIs particularly, students expressed anger at the slow pace of change in relation to institutional cultures, the predominantly white academic staff complement, and the fact that curricula, teaching, and assessment had not been adapted to respond to the more diverse student body. It is an indictment of these institutions that it took increasingly violent protests for academics to begin to understand the extent to which many students felt alienated from the institutions and their ways of working.

These protests were sparked largely by a University of Cape Town (UCT) postgraduate student who poured human waste on the statue of Cecil John Rhodes because students saw the statue as a symbol of an institutional culture of alienation, racism, and exclusion (Mamdani, 2016). These protests quickly spread to other institutions, disrupting academic activities and, in some instances, led to violence, injury, and the destruction of property. At Rhodes, the Rhodes So White movement raised similar issues related to calls for the decolonisation of universities. The slogan "we can't breathe" was used to epitomise the nature of the suffocating institutional culture. The Open Stellenbosch movement tackled issues of racism more generally, and students at both Stellenbosch University and the University of Pretoria protested against institutional language policies (see Badat, 2016).

Early in 2015, the office of Institutional Culture and Equity at Rhodes organised a conference on curriculum. At this event a small group of black students and staff, with support from a group of postgraduate students from the University of the Witwatersrand, made very clear their anger at the slow pace of change in relation to curriculum at Rhodes. Soon after that, in solidarity with the UCT protesters, Rhodes students established the Black Students 
Movement. Naicker (2016) said of this movement, "They too were troubled by the institutional culture at Rhodes, the composition of academic staff, and the curriculum, which did not reflect the locality of the university or its place within the African continent" (p. 54).

By late 2015 and early 2016 at many institutions, including Rhodes, the student protests moved their focus to tuition fee increases, student debt, financial aid, and the desire for free higher education. These issues are strongly linked to the calls for decolonising education since they point to the continued racialised inequalities between the rich and the poor in South Africa (CMoloi, Makgoba, \& Miruka, 2017). Naicker (2016) argues that embedded in the student protests are deep concerns for the ways in which "race and class privilege have been reified in South African universities" (p. 53).

In the literature, authors offer a range of ideas regarding what is meant by decolonisation and they highlight different aspects of this complex process (De Oliveira Andreotti, Stein, Ahenakew, \& Hunt, 2015; Maldonado-Torres, 2011). For the purposes of our analysis we chose to use the concepts of epistemic inclusion/exclusion and social inclusion/exclusion to explore HoDs' understandings of the calls to decolonise HE.

\section{Epistemic and social inclusion/exclusion}

At the heart of curriculum is the selection of knowledge to which students are introducedthe disciplinary canons that are drawn from. Given the history of colonialism and apartheid, the selection of knowledge has been strongly biased towards a Eurocentric canon that universalises knowledge, thus attributing truth only to a Western way of knowledge production. The reason for this bias towards a Eurocentric canon is that most academic staff members in SA universities are white and many black academics have themselves been schooled in Western/ Eurocentric traditions and find it difficult to think beyond their firmly entrenched disciplinary identities and canons (Heleta, 2016).

The curriculum content in most disciplines gives students the message that Western knowledge is all powerful and that it excludes the possibility of their seeing the value of other kinds of knowledge. As Leibowitz (2017) has pointed out, such curricula are "inadequate to solve the problems of social injustice and inequality of our times" (p. 101). The almost universal use of Western knowledge traditions in curricula has contributed significantly to the epistemic and social exclusion experienced by many students. It has resulted in "a hierarchy of superior and inferior knowledge and, thus, of superior and inferior people" (Grosfoguel, 2007, p. 214).

Mbembe (2015) and Ngugi (1981) argue that universities need to completely re-vision and restructure their curricula to ensure that the knowledge introduced to students includes a range of different knowledges and that Africa should be at the centre of all curriculum decisions. Visvanathan (2016) has talked about the need for bringing a "democracy of knowledges" together in dialogue. However, before this can happen academics need to be aware of the systems that have been, and still are, in place that have enabled epistemic/cognitive injustice. "Cognitive justice recognises the right of different forms of 
knowledge to co-exist but adds that this plurality needs to go beyond tolerance or liberalism to an active recognition of the need for diversity" (n.p.).

According to the Department of Education (DoE) (2008), after 1994 there was to be a "reorientation away from the apartheid knowledge system, in which curriculum was used as a tool of exclusion, to a democratic curriculum that is inclusive of all human thought" (p. 89). The student protests made it abundantly clear that there had been little progress in this regard. As the DoE report states, the curriculum "is inextricably intertwined with the institutional culture and, given that the latter remains white and Eurocentric at the historically white institutions, the institutional environment is not conducive to curriculum reform" (p. 91).

Particularly at HWIs, approaches to curriculum, teaching, learning, and assessment are still based on assimilationist models that position black students as deficient. It is therefore unsurprising that most black students in these institutions feel both epistemically and socially excluded and that this was highlighted during the student protests. Black students, particularly those from working class backgrounds, felt that the culture rendered their presence on campuses invisible (Mbembe 2015). Increasing numbers of black students in elite institutions (such as Rhodes) described experiencing these cultures as white. The protests made it clear that many students were highly critical of and questioned "the very foundations and practices of the liberal institution" (Naicker 2016, p. 57). Institutional cultures at HWIs made them feel separate from the socio-cultural life of the university and the academic project. Leibowitz (2017) has stressed that learning is not only cognitive, it is "active, affective and experiential" (p. 97); knowledge cannot be separated from coming to know.

According to the current vice-chancellor of Rhodes University, Sizwe Mabizela, decolonising means more than rethinking what and whose knowledge is selected for curricula. The student protests made it clear that black students at institutions such as Rhodes do not feel at home and that there is little "recognition and appreciation of different lived experiences that students bring with them into the classroom" (Mabizela, 2015, n.p.). Some of the pedagogic, and especially assessment practices employed are not aligned with who students are as people; students are arguing for "greater recognition that teaching and learning is not only an epistemological project, but, in essence, also an ontological one” (Vorster \& Quinn, 2017, p. 9).

From the preceding sections it is clear that the changes students called for were complex and required HoDs to interrogate their understandings of and responses to the students' calls and the implications of these for their roles as academic leaders.

\section{The roles of HoDs in higher education}

Nguyen's (2013) review of forty years of literature on the roles of HoDs in universities in the West recognises that while some roles are shared, others differ markedly across contexts. HoDs are usually responsible for managing staff, students, curricula, resources, and budgets; communication with senior management and others within and beyond the institution; and for 
the professional development of staff (Sewerin \& Holmberg, 2017). Globally, the roles of HoDs have become much more complex as a result of the influences of, among other things, the massification of universities and the concomitant increase in student diversity, the emergence of the knowledge economy, and the ubiquitousness of information and communications technologies. These changes have led to fiscal constraints and to increasing managerialism and the bureaucratisation of universities and probably represent the most serious challenges with which HoDs have to contend. These changes have led to the erosion of the traditional collegial leadership and decision-making roles of HoDs (Bryman, 2007). Jansen (2005) has argued that leaders who focus on "narrow administrative tasks" (p. 205) do so at the expense of much needed strategic approaches required to rethink and reposition institutions and their activities in response to contextual imperatives.

In South Africa, HoDs have also had to respond to the national policy agenda aimed at transforming HE by, inter alia, concentrating their efforts on changing the demographic profiles of their staff and students. Although there has been some focus on transforming curricula, pedagogy, and assessment to facilitate epistemological access for students from educationally disadvantaged backgrounds, the changes that have taken place have been woefully inadequate. Shields (2006) has warned that it is "[a]t our peril, [that] we ignore some of the increasingly strong critiques of educational organisations themselves and of their role in perpetuating inequalities in democratic societies" (p. 64). She has argued that what is needed to address these issues is transformative leadership. When HoDs focus only on management and administration they are more likely to pursue forms of leadership, such as transactional and transformational leadership, that focus inwards on the organisation rather than outwards on the society in which the organisation is located. Transactional leadership is about exchanges to achieve mutual benefit while transformational leadership is directed at improving the effectiveness of organisations (Shields, 2009). These modes of leadership are increasingly inadequate in a country such as South Africa because they ignore the influence of social inequality on the practices of educational institutions, including universities.

In the SA context where the effects of long-term racial segregation and discrimination are ongoing, what is needed is transformative leadership. Transformative leadership can be understood as "an exercise of power and authority that begins with questions of justice, democracy, and the dialectic between individual accountability and social responsibility" (Weiner, 2003, p. 89). It is essentially value-based leadership in a given social context that "can open up new possibilities for transformation and change" (Astin \& Astin, 2001, p. 2).

The aim of transformative leadership is thus to contribute to creating a socially just and democratic society that recognises diversity and offers equal opportunity to all (Shields, 2009). HoDs with a transformative agenda will therefore recognise the need to engage in dialogue with staff and students about difficult issues of equity, and equality, and inclusion as an integral part of their role. 


\section{Methodology}

The main research question for the study was: How do HoDs at Rhodes University conceptualise their roles in the context of the calls to decolonise higher education in South Africa? The data generation was undertaken in two phases. In the first phase, a questionnaire was designed for HoDs that was piloted and revised before it was administered electronically through google forms. The questionnaire was made available to all Rhodes HoDs, a total of 42. There were 20 responses (a $48 \%$ return rate). Completed questionnaires were labelled Q1 to Q20 and responses analysed to identify major themes. The data for this phase of the research was limited and did not allow for in-depth probing of HoDs' perceptions. It was intended to give us a broad sense of whether and how HoDs responded to the students' calls for decolonised higher education. Although not reported on in this article, the second phase of the data generation process involved in-depth semi-structured interviews with HoDs as well as document analysis. However, for this article we drew only on the questionnaire data to present a largely descriptive account of how the HoDs at Rhodes responded to the decolonisation calls, focusing specifically on the following questions.

- How do HoDs understand the calls to decolonise HE?

- How would you describe your role as an HoD at Rhodes?

- In what ways have the recent changes in the HE context influenced your role as an HoD at Rhodes?

- In what ways have HoDs' leadership practices changed in response to the calls for decolonisation?

Ethical approval was obtained for the project from the Centre for Higher Education Research, Teaching and Learning Ethics Committee and the Director of Human Resources. Although we undertook to try not to reveal individual participants' identities, we also acknowledged to participants (in writing) that, given the small size of Rhodes, they may be identifiable. In a bid to protect participants' identities we chose not to disclose the departments they head. We also made it clear that a study of this nature was bound to result in critiques of the University and even of the stances of individuals who participated in the study. However, we believe that critique is important in universities and that in this case we will ensure that the critique is constructive and does not result in any reputational risk for the University or individual HoDs.

In the following section we provide an analysis of the questionnaire data using some of the concepts from the literature on decolonisation and leadership in HE as discussed above to better understand how HoDs conceptualised their roles in a changing context and their initial responses to the students' calls for decolonisation. 


\section{Analysis and discussion}

\section{Understanding the need to decolonise higher education}

The responses to our first research question showed that the protests were a stimulus for HoDs to confront the reasons for the protest and to begin to grapple with what decolonisation might mean for the institution and for their role. From the data it is evident that tensions existed in the HoD collective since not all HoDs understood the need to decolonise at all or in the same way.

A number of HoDs expressed the opinion that the institution needed to "reconceptualise", "reshape", and "rethink" many of its existing ways of being and its practices. For some this entailed an imperative to take into account the African context "and what that means for institutional practices" (Q3). Some suggested a need to change approaches to teaching and research; for Q8, they need to "cater for the unique challenges we face in South Africa and Africa, while still remaining a world class university." For Q14, rethinking the university is about questioning "white western ways of relating, doing, and engaging; to resist arrogance and patronising knowledge-bearing, to embrace and explore diversity in the many dimensions of academia." Although these excerpts do not make explicit the complexity and diversity of different knowledge systems, they show that HoDs are beginning to grapple with what decolonising means. This suggests a need for more spaces of engagement in which university leaders and academics can share their understandings of how universities might be transformed. For Q5, "It would be useful to have forums where one can talk about and discuss [role reconceptualisation] but then again the results of this research could be a start."

In expressing their emerging understanding of decolonisation, some HoDs recognised the importance of challenging the relevance of the rules and symbols of universities in Africa such as Rhodes. For some, Rhodes' institutional culture and many of its traditions, policies, and practices needed to change if Rhodes is to become a truly African university. For example, Q15 expressed the opinion that if Rhodes were to be regarded as a "home for all" this could "only be achieved if current attitudes and values are challenged." Likewise, Q3 described how "reshaping universities would include reviewing institutional practices, rituals and symbols, amongst other things."

In addition, critiquing taken-for-granted curricula and teaching and learning practices was viewed as crucial for decolonising the academic project. Q3 challenged colleagues to examine "whether our curricula can reflect the (South) African and global South contexts more appropriately" and Q2 underscored the need to "introduce worldviews that have hitherto been marginalized, and sometimes even labelled in very problematic and stereotypical ways."

Some HoDs have begun to understand, in theory at least, that "real transformation will entail the radical process of including the methods, people and ideas that have been systematically excluded from our society" (Alasow, 2015, n.p.). However, it remains to be seen how this theoretical understanding has been or will be translated into transformed practices. 
Although, while the majority of HoDs (approximately 80\%) seemed prepared to engage at some level with the calls of the protesting students, others were either not persuaded by the decolonisation call or thought it had little bearing on their disciplines: for Q7, "The idea applies little to us" and Q10 said, "I have no understanding of what it means. The term decolonise is so general." Q17 referred to the call as "poorly defined populism."

Understanding these responses, particularly in relation to the differences between the humanities and the sciences, requires further investigation and will be taken up in the second phase of this research.

\section{HoD role conceptualisation}

The roles of the HoDs at Rhodes were understood generally in relation to the traditional pillars of HE: teaching, research, and community engagement. For example, Q13 spoke of his/her role as providing "academic leadership in terms of [all aspects of] the academic project." Because not all HoDs understood decolonisation in the same way, tensions emerged in how they conceptualised their roles. The tensions were caused by the struggle to navigate the messiness of balancing the transformative leadership and bureaucratic management aspects of their role. The data suggests that while some HoDs wished to exercise transformative leadership which would contribute to enhancing social justice and democratic values, changes in the HE landscape globally, and at Rhodes, have made this difficult. This has led to many of them seeing their roles as predominantly managerial and administrative. As Q18, put it, "HoDs have less time to concentrate on leadership as they are required to be administrators instead" while Q20 said, "I don't see myself as a 'leader' [but] more as an administrator."

Historically, policies and practices at universities like Rhodes have privileged academic freedom, a heterarchical division of labour and what Bush (1995) refers to as a collegial leadership model. However, recent changes resulting from neoliberal influences have resulted in bureaucratic, top-down forms of management, which are perceived by the HoDs as undermining their ability to exercise meaningful transformative leadership. Q20 said, "There's a huge amount of bureaucracy to get on top of; and endless, endless meetings!" For Q12, instead of values-based leadership, the role "has somehow become about ensuring safety of buildings and building layers of bureaucracy, and less about the 'academic project." These excerpts suggest a growing sense of frustration on the part of HoDs in response to the shifting institutional norms.

Thwarted by these institutional constraints, a few HoDs argued that what was needed were more enabling conditions for exercising transformative leadership in more meaningful ways: "let HoDs 'read' the situation for themselves and give them space to 'lead the way out' as partners with departmental staff, not bureaucrats expected to 'toe the line, or else' type of thing" (Q2). Q17 called for a climate in which HoDs have more influence "to shape the academic project and push back on the considerable administrative bureaucracy." However, Q4 observed that some HoDs "have a tendency to operate under a "deficit mentality"" and suggested that they make excuses for "why things cannot be done rather than what can be 
done." In addition, this respondent commented that at Rhodes "we take a long time to make decisions, indicating a lack of decisiveness."

Despite the tensions highlighted in this section, the discussion that follows provides examples of individual HoDs beginning to respond in concrete ways to the issues arising from the student protests.

\section{Actions in response to the decolonisation calls}

While a few HoDs were perplexed and resistant to calls to decolonise HE, for the majority, the calls were a stimulus to rethink their academic leadership role. Predominantly schooled in Western ways of thinking, some HoDs admitted that until the protests, they were oblivious to, or underestimated the extent of, dissatisfaction in the broader student community. The disruption of the status quo catalysed HoDs into seeing, listening, and acting in different ways. It opened up new possibilities for transformation and change and the opportunity to lead in more transformative ways. Actions in response to the protests varied. For Q11, a starting point entailed "[taking] a good hard look at our university culture, staff and curriculum and [making] ourselves more representative of, and relevant to, the African context and the majority of our students." The imperative for HoDs was now to listen more carefully and, following Engeström (2015), hear the students, in a spirit of multivoicedness. This call to action is captured here.

My colleagues and I are aware that the student protests are in a sense an indictment of the fact that we have not sufficiently understood the extent to which many students have felt alienated from the institution and its ways of working, including in relation to curricula and pedagogic practices. As HoD [my] role is to influence academic practices, it is important that I understand the substance and implications of the students' calls for changing the institution and to consider how best to respond to the calls. (Q3)

HoDs reported on a number of new practices that were introduced (or that they were planning to introduce with colleagues in the departments) that aimed to mitigate the effects on students of epistemic and/or social exclusion.

\section{Epistemic inclusion}

In the data it was evident that many HoDs believe that Western forms of knowledge, traditionally privileged in most departments at Rhodes, should be open to critique. Q11 explained the importance of "recognising different perspectives, values, worldviews, indigenous knowledge, African scholars and scholarly work, locally applicable examples and case studies, social justice and economic issues especially in relation to living in the global South." This growing awareness of the importance of knowledges from the global South is also illustrated in Q4's response.

We always stress locality (global/local) in our context. Our focus is on leadership for sustainability. We apply our 4 E model: Economy, Ethics, Ecology and Equity. We 
actively teach African Leadership. Our qualification is internationally accredited. So, for us it is a constant interrogation. We are looking at initiatives to introduce the other official languages into our teaching.

The protesting student voice alerted HoDs to the need for critical curriculum engagement and revision; for Q7, “[We need] to make the curriculum more African.” Extending this idea, Q3 described how "we have been made more aware of what we include and exclude from our curricula and are thinking about how we can make it possible for [students] from a broader range of contexts and academic experiences and practices to complete our courses successfully."

From the questionnaire data it would seem that although some progress has been made in terms of understanding the need for challenging traditional disciplinary knowledge, not all HoDs are fully aware of how current knowledge traditions have contributed to epistemic injustice. Not all academics at Rhodes seem ready to move beyond tolerance of differences to an understanding of what an active recognition of drawing on a plurality of knowledges may mean for their curricula (see Visvanathan, 2016). The data points to differences among HoDs from different disciplinary backgrounds, with those from the sciences particularly finding it more difficult to envisage thinking beyond traditional scientific knowledge.

\section{Social inclusion}

In addition to acknowledging the importance of epistemic justice, most of the respondents also recognised the importance of social inclusion for student learning. In the face of the disruptions, a number of the HoDs spoke about their understanding that it was important for them to create a culture of inclusivity in their departments so that all students and staff felt that they belonged. Diversity in the staff and student population and the need for different kinds of relationships were both acknowledged. As Q9 observed, "Relationships are changing, at least for a few members of staff, to move away from a 'colonial' model." Regarding the increasing diversity of the student population and efforts towards social inclusion, Q4 said, 'Different views must be respected. There isn't a one size fits all. I certainly don't want to suggest that this is a threat, it is a great opportunity." The protests, it seems, triggered an awareness of the need for continued efforts towards more inclusive ways of being, for students and staff alike. What is not clear from the data and needs to be probed further is whether HoDs (and their colleagues) have really understood how alienating the culture of an institution like Rhodes can be for some black students and staff and whether they have moved beyond seeing their role as facilitating the assimilation of black students and staff into the existing middle-class, white culture at Rhodes.

From the data it emerged that tensions were experienced within some departments in relation to how academics and HoDs responded to the protests. "Certainly, HoDs had to deal with crisis issues, unhappy staff and students . . coping with stressful situations" (Q4). Q16 described how "some colleagues are impatient with the rate of change; others are threatened and uncomfortable. Dealing with people's heightened emotions has become the workplace norm, under these circumstances." Q6 was of the view that "it's hard to convince people that 
change is good. There is a lot of reticence out there, a strong aversion to risk." Given the increasingly volatile situation during the protests, it is unsurprising that HoDs were concerned about the risks attached to their actions: as Q16 said, "It seems that the margin for error has increased, and any misstep is incredibly costly, personally and professionally." These findings echo Heleta's (2016) view that the calls for decolonisation have unsettled many SA academics, but in different ways and for different reasons. This is another aspect that needs dedicated attention in future research projects.

Emerging from the data was a strong understanding that as student cohorts have become increasingly diverse, academics need to pay attention not only to what is taught, but also to issues of teaching, learning, and assessment. For example, as Q11 put it, "So changes in the content we teach are important, but also the way we teach. We need to think about new and different ways for students to learn and develop knowledge." Q5 spoke of a renewed sensitivity to "content, teaching methods, text books prescribed and guest speakers used. There is more open questioning as to what is appropriate and relevant." Q16 said that s/he had "motivated for a change from sat exams to continuous assessment as being more fair, just, inclusive and appropriate to the subject."

A number of respondents expressed their awareness of the pedagogic implications of English as the language of learning and teaching at Rhodes: "I also often wonder about the issue of language and whether we should give this more consideration" (Q11). Q19 noted that there was a need to change assessment practices that favoured students with good English writing skills, while Q13 reported that in his/her department "the language of teaching and learning has become flexible, as it has become easier to switch codes . . . and our tutors helped a lot in this regard." Q1 described the need to challenge the linguistic status quo at universities in order to ensure that "students achieve academic literacy in English in order to make epistemic access possible, while at the same time affirming students' linguistic (and also class, gender, regional and cultural) diversity." These insights are significant and show that some HoDs and academics are thinking deeply about the role of language as an instrument of oppression and exclusion in colonial universities. They are beginning to understand the importance of using indigenous languages as resources for teaching and learning.

In summary, we argue that the data indicates that the majority of HoDs who responded to our questionnaire have begun to engage with issues of epistemic and social inclusion and have considered how important both are for ensuring that all students are given equal opportunities to learn and flourish.

\section{Conclusion}

The tumultuous protests of 2015 and 2016 were an urgent call for the decolonisation of South African universities. Rhodes University, an historically white institution, was not exempt from this call. With its colonial history and its entrenched culture of whiteness, the university has struggled, since the official end of apartheid, to eradicate its racist, patriarchal discourses 
and practices and bring about radical transformation which affirms and respects difference and the creation of an inclusive culture (Meth, 2017).

Despite the prevalence of a strong transformation discourse in the HE sector nationally, few academics at Rhodes had engaged deeply with it, perhaps because of a discourse of excellence prevalent in the Institution. It was thus only when the stronger decolonisation discourse was overtly foregrounded during the curriculum conference and the protests of 2015 and 2016 that many more academics and HoDs at Rhodes began to engage more seriously with what decolonisation could mean for them, their colleagues, and their students.

Against this background, our research sought to understand how HoDs conceptualised their roles in response to the calls to decolonise. From our analysis of the data it is clear that the student calls had disrupted the taken-for-granted culture and practices in many departments at Rhodes, more so in the humanities than in some science departments. For the most part, HoDs acknowledged that, prior to the protests, they had not paid sufficient attention to the increasing student diversity in their departments and had not adequately considered student feelings of exclusion and othering as a consequence of this rapidly changing student body. The protests therefore prompted many HoDs into action; collectively, with willing colleagues, they began to reflect on and critique the social and epistemic practices in their departments. Epistemically, this has led to many beginning to question the knowledges privileged in curricula. Socially, this has led to an increased awareness of, and value attributed to, social differences in the student body, particularly in relation to race, gender, language, and socio-economic backgrounds, and, most significantly, what these differences mean for teaching, learning, and assessment.

A closer reading of the data, however, revealed that an incremental approach to change is preferred by many HoDs. As custodians of the academic project, they are open to tackling discourses of colonisation, patriarchy, racism, sexism, and the culture of whiteness at Rhodes, but they are cautious, rather than radical, in this endeavour. This stands in stark contrast to the protesting students who called for radical transformation and the immediate inclusion of "methods, people and ideas where they have been systematically excluded" (Alasow 2015, n.p).

This complex and fraught array of challenges faced by HoDs during the protests, propelled many of them into rethinking their academic leadership roles. The protests highlighted that traditional forms of leadership that focus only inwards on the organisation currently have little purchase in HEIs because they carry with them the legacies of "patriarchy, 'governmentality,' hierarchical administrative practices, authoritarianism, and domination" (Weiner, 2003, p. 89). Some HoDs began to realise the need for an alternative form of leadership that could focus outwards on society, one that would embrace dialogue with staff and students about difficult issues of equity, equality, and inclusion as an integral part of their role. Transformative leadership, as such an alternative, recognises that higher education is not only about individual achievement but also about public good; it is about democratic citizenship and participation of all in civil society (Shields, 2009). HoDs, in their role as transformative leaders, are therefore called on to engage with students, listen genuinely to 
them, take cognisance of what they say, and create opportunities for them to participate in decision-making practices in order to develop as democratic citizens.

There is still much work to be done at Rhodes before it can be called a home for all. To date, and despite the attempts of many HoDs to bring about changes in their departments, the institution "has yet to succeed in uprooting inherited cultures and practices and bringing about the far-reaching transformations that are necessary and long overdue" (Meth, 2017, p. 105).

\section{References}

Alasow, J. (2015, March 23). What about 'Rhodes University must fall?' Daily Maverick. Retrieved from https://www.dailymaverick.co.za/opinionista/2015-03-23-what-aboutrhodes-university-must-fall/\#.WJXHFDidfTQWhat about 'Rhodes (University) must fall

Astin, A., \& Astin, H. (2000). Leadership reconsidered: Engaging higher education in social change. Retrieved from https://files.eric.ed.gov/fulltext/ED444437.pdf

Badat, S. (2009). Theorising institutional change: Post-1994 South African higher education. Studies in Higher Education, 34(4), 455-467.

Badat, S. (2016). Deciphering the meanings, and explaining the South African higher education student protests of 2015-2016. Pax Academia, 1, 71-106.

Becker, A. (2017). Rage, loss and other footpaths of subjectification, decolonisation and transformation in higher education. Transformation in Higher Education, 2, 1-7.

Bryman, A. (2007). Effective leadership in higher education: A literature review. Studies in Higher Education, 32(6), 693-710.

Bush, T. (1995). Theories of educational management (2nd ed.). London, UK: Paul Chapman.

CMoloi, K., Makgoba, M. W., \& Miruka, C. O. (2017). (De)constructing the \#FeesMustFall campaign in South African higher education. Contemporary Education Dialogue, 14 (2), 21-23.

De Oliveira Andreotti, V., Stein, S., Ahenakew, C., \& Hunt, D. (2015). Mapping interpretations of decolonization in the context of higher education. Decolonization: Indigeneity, Education \& Society, 4(1), 21-40.

Department of Education. (2008). Report of the ministerial committee on transformation and social cohesion and the elimination of discrimination in public higher education institutions, Final Report. Pretoria, RSA: Department of Education. 
Engeström, Y. (2015). Learning by expanding: An activity theoretical approach to development research (2nd ed.). Cambridge, UK: Cambridge University Press.

Grosfoguel, R. (2007). The epistemic decolonial turn: Beyond political-economy paradigms. Cultural Studies of Science Education. Retrieved from http://www.tandfonline.com/doi/full/10.1080/09502380601162514

Heleta, S. (2016). Decolonisation of higher education: Dismantling epistemic violence and eurocentrism in South Africa. Transformation in Higher Education 1(1), 1-8.

Jansen, J. D. (2005). The color of leadership. The Educational Forum 69, 203-211.

Leibowitz, B. (2017). Cognitive justice and the higher education curriculum. Journal of Education, 68, 93-112.

Mabizela, S. (2015). Graduation 2015: Vice-chancellor's welcome address, Grahamstown, RSA. Retrieved from http://www.ru.ac.za/search/?q=Dr+Mabizela+Graduation+address+2015.

Maylam, P. (2005). Rhodes University: Colonialism, segregation and apartheid, 1904-1970. African Sociological Review, 9(1), 14-22.

Maldonado-Torres, N. (2011). Thinking through the decolonial turn: Post-continental interventions in theory, philosophy, and critique-An introduction. TRANSMODERNITY: Journal of Peripheral Cultural Production of the LusoHispanic World, 1(2), 1-15.

Mbembe, A. (2015). Decolonizing knowledge and the question of the archive. Aula Magistral Proferida. Retrieved from https://wiser.wits.ac.za/system/files/Achille\%20Mbembe\%20$\% 20$ Decolonizing\%20Knowledge\%20and\%20the\%20Question\%20of\%20the\%20Arc hive.pdf.

Mamdani, M. (2016). Between the public intellectual and the scholar: Decolonization and some post-independence initiatives in African higher education. Inter-Asia Cultural Studies 17(1), 68-83.

Meth, O. (2017). \#FeesMustFall at Rhodes University: Exploring the dynamics of student protests and manifestations of violence. In M. Langa (Ed.), \#Hashtag: An analysis of the \#FeesMustFall movement at South African universities (pp. 97-107). Johannesburg, RSA: Centre for the Study of Violence and Reconciliation.

Naicker, C. (2016). From Marikana to \# Feesmustfall: The praxis of popular politics in South Africa. Urbanisation and Health Newsletter 1(1), 53-61.

Ngugi, W. T. O. (1981). Decolonising the mind: The politics of language in African literature. Nairobi, Kenya: East African Educational. 
Nguyen, Thi Lan Huong. (2013). Middle-level academic management: A case study on the roles of the heads of department at a Vietnamese university. Tertiary Education and Management 19(1), 1-15.

Sewerin, T., \& Holmberg, R. (2017). Contextualizing distributed leadership in higher education. Higher Education Research \& Development 36(6), 1280-1294.

Shields, C. M. (2006). Creating spaces for value-based conversations: The role of school leaders in the 21st century. Institute for the Study of English in Africa 34(2), 62-81.

Shields, C. M. (2009). Transformative leadership: A call for difficult dialogue and courageous action in racialised contexts. Institute for the Study of English in Africa $37(3), 53-68$.

Visvanathan, S. (2016). The search for cognitive justice. Retrieved from http://www.indiaseminar.com/2009/597/597_shiv_visvanathan.htm

Vorster, J., \& Quinn, L. (2017). The "decolonial turn": What does it mean for academic staff development? Education as Change 21(1), 31-49. Retrieved from http://dx.doi.org/10.17159/1947-9417/2017/853

Weiner, E. J. (2003). Secretary Paulo Freiré and the democratization of power: Toward a theory of transformative leadership. Educational Philosophy and Theory, 35(1), 89106. 